\title{
Voltage Control in Active Distribution Grids: A Review and A New Set-up Procedure for Local Control Laws
}

\author{
S. Mina Mirbagheri, Davide Falabretti, Marco Merlo \\ Energy Department \\ Politecnico di Milano \\ Milan, Italy \\ sayedehmina.mirbagheri@polimi.it
}

\begin{abstract}
Planning, operation and control of active distribution grids by increasing the number of dispersed generators is becoming more important but also more complex. Hence, the importance of controlling the voltage is highlighted in many research papers. Traditionally, in passive distribution networks the voltage rise has been mitigated by network reinforcement. Nowadays, local voltage control, coordinated voltage control and centralized voltage control have been discussed for active networks in research papers. Although all the approaches have been proven to solve the problem of voltage rise in distribution grids, using plenty of sensors to gather huge number of measurement could cause complexity. This paper represents a literature review of different voltage control approaches in active distribution grids and proposes a new procedure to set up a local voltage control law devoted to properly manage the voltage profile (e.g. minimizing losses on MV feeders).
\end{abstract}

Index Terms-dispersed generation, active distribution grid, voltage control, hosting capacity.

\section{INTRODUCTION}

$\mathbf{T}$ he increasing penetration of Dispersed Generation (DG) mainly based on Renewable Energy Sources (RES), as a supplement to centralized generation, has caused new challenges in modeling, operation and controlling of the Medium Voltage (MV) distribution grid. Although DGs could take some advantages from RES production such as sustainability, less maintenance and low carbon emission, since DGs power injections to the grid are not coordinated with the actual distribution grid, it can cause power quality and reliability degradation such as harmonics, voltage profile and interface protection problems and moreover it may increase system losses and operational costs [1]-[4].

The fast increasing of DG connections may affect the supply quality. In fact, voltage profile along the feeder have been influenced and over voltage at the DG's Point of Common Coupling (PCC) may occur [5], [6]. The voltage increase along the feeder leads to power flow decreasing in the HV/MV transformer which cause load compensation decreasing. Thus, new voltage regulation approaches are required which have to act not only through substation measurements [7], [8].

In the literature, several methods are proposed for voltage regulation. The first step of distribution grid's control strategies is based on local management which is already expressed by national standard, e.g. the Italian Technical Committee (TC) 316, and international standard IEC [9]. Since the possibility of reverse power flow by increasing the penetration of DGs into the grid is arising, distribution system is transforming to the active distribution network. By this transformation, Distribution System Operators (DSOs) can solve voltage problems by controlling grid's generation and consumption [10]. To do so, an active network management will be needed which, by real-time communication and control, may provide better DG integrations [11].

In fact, the voltage regulation proposals can be classified into 3 main groups: 1) Local voltage control, which is based on local PCC measurement, 2) Coordinated Voltage Control, and 3) Centralized Voltage Control, which are the evolution of local control, working with telecommunication system. It is worth mentioning that the purpose of voltage regulation is not only the elimination of voltage rises and the increasing of Hosting Capacity (HC). Voltage regulation is a resource to improve and optimize the entire electrical grid according to different objective functions, such as system losses reduction or power factor optimization. The aim of this paper is representing a literature review of the aforementioned voltage regulation methods and propose a new procedure to set up a control law to respond to the distribution challenges and needs. The structure of this paper is as follows: section II represents local voltage control, section III and IV is devoted to coordinated and centralized voltage controls. In section V the issues and needs according to these methods discussed, and finally in section VI the new procedure to set up the control law is proposed. At the end, section VII concludes this study.

\section{Local Voltage CONTROL}

Local voltage control, known as decentralized method, uses local information to allow more DG to connect to the grid increasing HC. This method is used where the communication and optimization tools are limited. Thus, each DG works separately and uncoordinated with other devices, leading to less expenses [12]. The local voltage control is obtained with two contributions: the regulatory of on load tap changer in primary substation and the power factor control of DG units. 


\section{A. On Load Tap Changer (OLTC)}

The automatic tap changer is controlling the voltage of MV bus-bar at Primary Substation (PS). To do so, the voltage setpoint is determined (in the best case) by offline Optimal Power Flows (OPF) in order to provide a suitable voltage profile for the whole feeder [13]. In order to manage the increasing number of DGs, studies related to the operating power factor, size and location of the DGs are required [14], [15].

Usually, OLTC regulation performs considering a Line Drop Compensation (LDC), based on the resistance (R) and reactance $(\mathrm{X})$ of the feeder to regulate the voltage at transformer terminal [16]. Actually, by LDC measuring the secondary current simulates the voltage drop along the feeder between transformer terminal and load [17], [18]. The fundamental operation of OLTCs with or without using LDC has been studied in [19].

Since the voltage rise may affect the Automatic Voltage Control relay (AVC) and subsequently causes regulation problems, in [16] different modern control schemes are discussed. The methods for voltage control improvement are including Enhanced Transformer Automatic Paralleling Package (TAPP), to reduces the circulating current between transformers, and super TAPP $n+$ relay, the enhanced TAPP scheme which has the ability to estimate the RES output current. In [20], a setpoint control algorithm of AVC is proposed. State estimationbased OLTC is suggested in [21].

\section{B. Reactive Power and Power Factor Control (PFC)}

It is well known that DG injections drive a voltage rise in the MV feeders. Actually, these generators could be coupled with additional compensators to regulate the voltage in its limits [22]. Static compensators (STATCOM), D-STATCOM, static VAR compensators (SVC), fixed capacitor banks and shunt capacitor banks have been investigated in [23]-[26], although some of these devices are costly.

Generally speaking, PFC could control the system's voltage by increasing the hosting capacity of the distribution grid [11], [27], [28]. There are many studies about the combination of various methods with PFC, which allow for some advantages such as reliability, efficiency and flexibility [29], [30].

In [5], [31], 4 different local control strategies have been exploited according to European technical standards, as listed in the following: $\operatorname{Law} A$ ) control of tangent of $\phi$ according to the PCC voltage $(\tan \phi=f(u)) ; L a w B)$ control of reactive power according to the PCC voltage $(q=f(u))$; $L a w C$ ) control of tangent of $\phi$ according to the real power injected $(\tan \phi=f(p))$; LawD) control of reactive power according to the real power injected $(q=f(p))$. In Fig. 1 the aforementioned control laws are presented.

\section{Coordinated Voltage Control (CVC)}

This real time control acts according to control rules taking into account the needs of the whole distribution network. This method is suitable for simple networks with less control possibilities and optimization tools. The CVC holds the information of network topology and electrical characteristic of each feeder
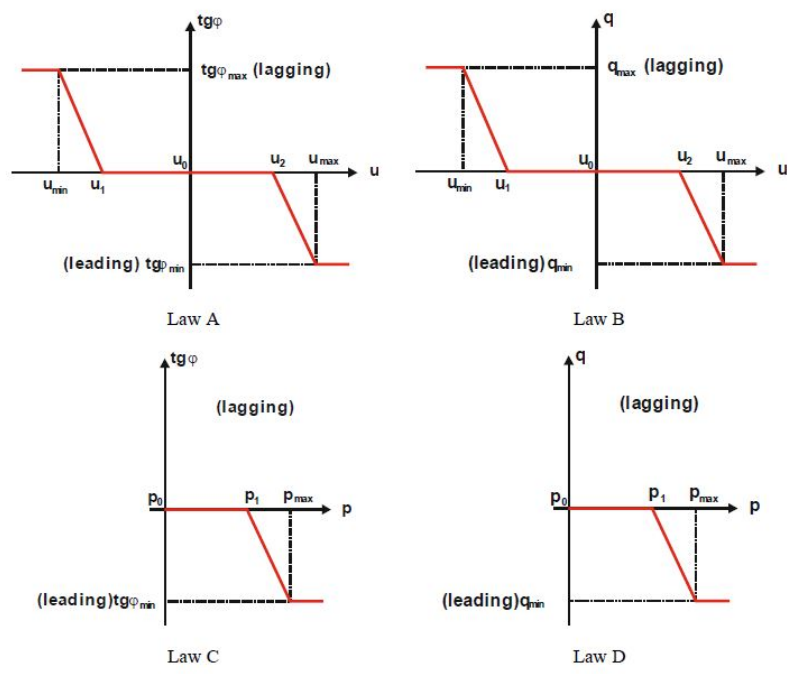

Fig. 1. Local voltage control strategy.

connected to the PS. The voltage control logic is based on two categories: 1) In case of normal operation condition no signal is sent to the CVC and the system is working according to the local voltage control strategy; 2) in case of critical condition, after receiving a warning signal $\mathrm{CVC}$ will elaborate the collected information to apply proper regulation actions. The goal of CVC is to improve the system operation toward an optimum.

The easiest method of CVC which is controlling substation voltage based on voltage lower and upper bound has been studied in [32]. In some proposed approaches, only reactive power compensators have been used in order to keep the voltage at the permissible level [33]. A new CVC method with reactive power managment scheme has been studied in [34]. Besides, in [35]-[38], the authors proposed a combined method of SVC by injecting reactive power and step voltage regulator by changing tap position according to the received information from sensors in the distribution line which could be able to keep the voltage lower than the maximum allowed. Moreover, in [39], [40], active power control has been implemented in order to control the voltage, while distributed methods using multiagent systems for CVC have been studied in [33], [41].

The aforementioned approaches are useful in simple and small networks, however by increasing the number of objectives, the control rules could become complicated. Hence, optimization algorithms have been used in many research papers. Genetic Algorithm (GA) has been used in [42]-[44]. In addition, Particle Swarm Optimization (PSO) algorithm has been investigated in [45]. Two new CVC algorithms, focused on time domain simulation and statistical distribution network planning, have been discussed in [46]. The combination of local-learning algorithm and nonlinear programming for computational time reduction was implemented in [42], [47]. In [48], a new two-stage voltage control scheme for controlling OLTC, capacitor banks and DGs using micro genetic algorithm 
and recursive genetic algorithm has been used. This method is based on finding the optimal reactive injection looking for the minimization of the power losses. Structural changes to minimize the operational conflicts by giving the priority in action to the resources close, based on the electrical distance, has been proposed in [49]. Finally, the importance of reliable communication infrastructure and the quality of service in CVC was discussed in [50].

\section{Centralized Voltage Control}

This last-step-regulation procedure needs a complete and continuous communication between PS and the sensors widespread on the distribution network. It is based on continuous OPF calculations of the network model which is obtained by the state estimator. In each cycle, the obtained voltage setpoints are delivered to the local DG. Actually, the centralized voltage control is an advanced control based on OPF, it has to generate a new voltage set-point by comparing the optimum value created by OPF and the measured value in order to adopt the optimum according to the current network status.

There are many intelligent techniques which are used for centralized control to formulate different type of objective functions [51]-[53]. The advantage of using these methods is to provide optimized solution compared to the conventional methods and, as they have flexibility in defining constraints, to effectivelly handle the nonlinear programming. GA, PSO, Evolutionary PSO, Discrete PSO, sensitivity theory, tabu search, Artificial Neural Network, fuzzy logic and multi agent are extensively report in literature review [54]-[56]. In these studies, by solving a constraint optimization problem for minimizing the system losses, control actions are scheduled to reactive power suppliers.

An improved centralized voltage control of OLTC and Static Voltage Regulator based on standard communication lines and automation server has been studied in [57]. The voltage fluctuations are forecasted using JIT modeling. Similarly, in [58], day-ahead load forecasts using GA are exploited in order to define the optimal dispatch schedule of OLTC and shunt capacitor. The PSCAD/EMTDC network model with different load profiles and dynamic loads is validated by the OPF developed in [59].

\section{NEEDS AND ISSUES}

As discussed in the previous sections, voltage control methodologies and approaches are investigated and discussed in the literature as a means of enhancing the distribution grid HC. Table I, shows the different approaches comparison [60]; for some approaches to regulate the voltage along the system and hold it in the allowable limits, an accurate knowledge about each node's voltage is required. However, due to lack of (or limited number of) complete Supervisory Control And Data Acquisition (SCADA) in distribution networks, real time measurements are rarely available through feeders and only are available at PS. To compensate this shortage, state estimation of measurements has to be done by sensors and communication assets to evaluate voltage profiles and to dispatch the
DG units and the other resources available in the network accordingly. However, state estimation procedures based on a very limited number of measures typically are affected by uncertainty and errors which may cause wrong decisions. On the other hand, aligning sensors for each node of the distribution system is very costly and unaffordable. Hence, a cost effective approach to set up the voltage law has to be proposed to cope with all of these problems.

TABLE I

DECENTRALIZED, COORDINATION AND CENTRALIZED VOLTAGE CONTROL COMPARISON.

\begin{tabular}{|c|c|}
\hline $\begin{array}{c}\text { Decentralized } \\
\text { methods }\end{array}$ & $\begin{array}{c}\text { Coordinated and Centralized } \\
\text { methods }\end{array}$ \\
\hline local control & vast control \\
\hline needs no communication & needs vast communication \\
\hline with no coordination & with vast coordination \\
\hline Affordable & costly \\
\hline
\end{tabular}

\section{Proposed Method}

The strategy proposed in this paper has been developed according to the DSO needs and European technical standards. DSO are in charge to set the local voltage control on DG power plants according to Fig. 1. Thus, generation units could be considered in order to develop new algorithms for the reactive resources management in the MV distribution networks. This can be done by corrective adjustments of the reactive production of a single generator. In particular, each generating unit has to give reactive support in those situations in which its production would lead to voltage violation, according to the standard EN 50160. However, no literature could be found for this purpose. The procedure has been proposed in this paper is based on the optimal reactive power flow (ORPF), a non linear problem with continue and discrete variables. In the proposed strategy, the ORPF operates off-line on the basis of a historical network behavior. The goal of the procedure is to statistically set up the parameters of the local voltage control law. With respect to the proposed approach, each reactive resource operates locally and the parameters of the local characteristic are adjusted according to the output of an optimum computation. With respect to such an approach, no communication infrastructure is necessary since still is a local voltage control.

ORPF objective function could be losses minimization, generator reactive power minimization and voltage deviation of each node from the related value minimization. ORPF constraints can be defined as: voltage limits of buses, reactive power capability limits of generators and power factor limits at the substation. With respect to the proposed approach, several grid working conditions have to be evaluated (e.g. evaluating the power injections over a solar year) solving for each one the ORPF problem, then interpolation of the ORPF outputs by a defined mathematical law, as those presented in Section II, has to be done. The final goal is to properly define the local voltage regulation setting. In order to validate the model, the network losses, maximum, minimum and average voltage of 
generator PCC and standard deviation of the voltage at PCC should be compared with ORPF outputs. If the indexes meet the requirements, it can be adopted for the real case. In the following the mathematical overview of ORPF and its equality and inequality constraints are detailed.

$$
\begin{gathered}
P_{g, k}-P_{d, k}-V_{k} \sum_{m=1}^{N} V_{m} Y_{k m} \cos \left(\delta_{k}-\delta_{m}-\theta_{k m}\right)=0 \\
Q_{g, k}-Q_{d, k}-V_{k} \sum_{m=1}^{N} V_{m} Y_{k m} \sin \left(\delta_{k}-\delta_{m}-\theta_{k m}\right)=0 \\
V_{\min }<V_{i}<V_{\max } \\
I_{i j}<I_{\max } \\
\overline{P_{i}}-P_{c a l c, i}(V, \delta)=0 \\
\overline{Q_{i}}-Q_{c a l c, i}(V, \delta)=0 \\
Q_{\min , i} \leqslant Q_{i(V, \delta)} \leqslant Q_{\max , i}
\end{gathered}
$$

where $P_{g, k}, Q_{g, k}, P_{d, k}$ and $Q_{d, k}$ demonstrates active and reactive power of the generators and demand absorption of bus $k$ respectively. $V$ and $\delta$ are voltage magnitude and voltage phase respectively. $N$ is the total number, whereas $Y$ and $\theta$ are magnitude and the phase of the bus admittance.

In the following, the local voltage control law by interpolation of ORPF results for a $15 \mathrm{kV}$ radial MV distribution network is discussed. The objective function is losses minimization and the constraints are voltage limits of each node and reactive power capability limits of generators. The time period is one year with the step of one hour (8760 steps). Since in passive condition the voltage along the feeder is decreesing [61] for each feeder three different locations are considered for DG connection, the first $(G E N-01)$, the last $(G E N-03)$ and the middle $(G E N-02)$ node of the feeder under evaluation, which are defined according to the electrical characteristic of the feeder itself, Fig. 2 represents the defined nodes. The setting procedure for $l a w B$ is carried out considering two rated power of generators, the first (4 MW) correspond to an injection not causing voltage violation in the grid, the second (sized at $6 \mathrm{MW}$ ) represent a big generator that in some samples causes nodal overvoltages.

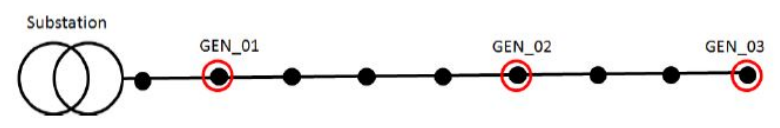

Fig. 2. DG units location.

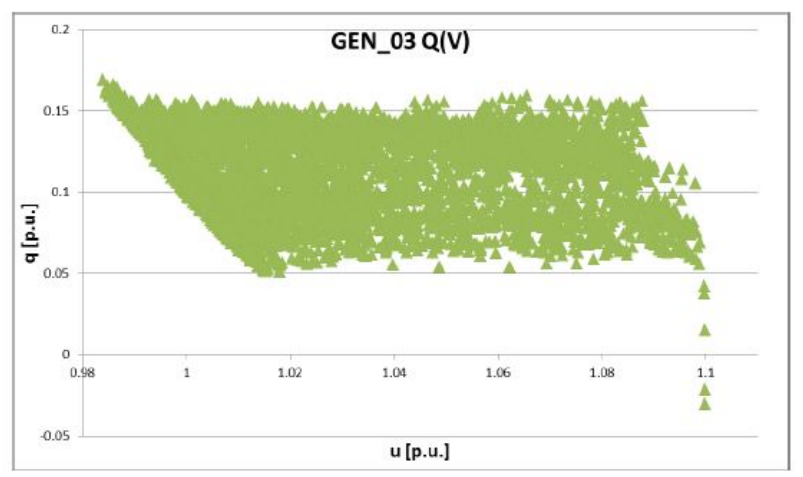

Fig. 3. ORPF outputs at $4 M W$ for GEN-03.

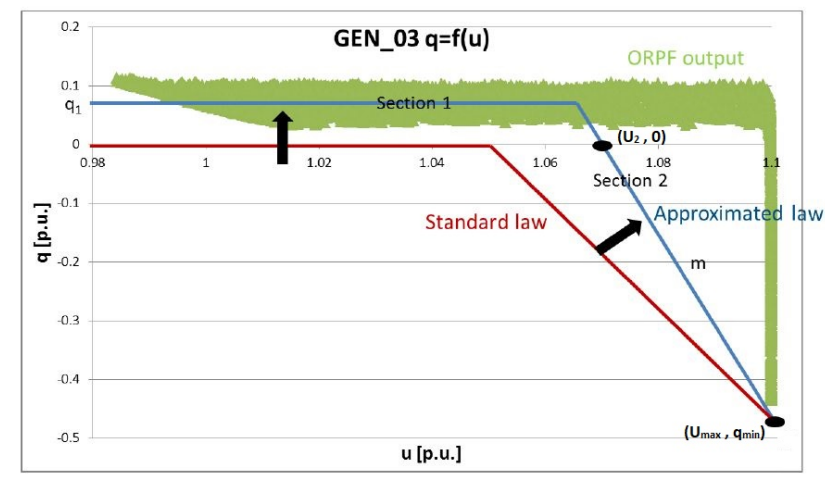

Fig. 4. Interpolation of GEN-03 ORPF output to the local control LawB at $6 M W$.

For each time sample, one of the mentioned generators is connected to the defined nodes and for each condition the ORPF has been solved. For brevity only results of the most critical node, i.e. the one depicting more violations (GEN03 ) have been showed here. The ORPF outputs of the $G E N-$ 03 for both injected values are shown in Fig. 3 and Fig. 4. The ORPF results depict that generators have to inject reactive power in order to support the voltage profile and reduce the network losses until the voltage is within the constraints. The mathematical law considered in the interpolation procedure is a linear piecewise law. Therefore, a linear function with only two piecewises (named Section 1 and Section 2) is considered in Fig. 4. Section 1 is represented by a constant line equal to the average between $5^{\text {th }}$ and $95^{\text {th }}$ percentile of reactive power value $q_{1}$ of all the operation points with voltage lower than $U_{2}$. Beside, section 2 of the piecewise function is represented by a line with a fixed negative slope. In order to guarantee a continuous function, Section 2 starts at a reactive power value equal to $q_{1}$ and it links the points $\left(U_{2}, 0\right)$ and $\left(U_{\max }, q_{\min }\right)$.

In order to check the settings, standard local voltage control is tested in the same network considering the same generation scenario. A comparison between the network losses calculated by the adopted new settings of the local curve $L a w B$ approximate (App.), the losses obtained with the standard settings of the LawB standard (St.) and losses optimized 
thanks to ORPF is reported in Fig. 5. The losses are computed with respect to the losses obtained in the passive network scenario, hence the relative network losses are equal to:

$$
p_{\text {Loss }}=\frac{P_{\text {Loss }}-P_{\text {Loss-passive }}}{P_{\text {Loss-passive }}} .
$$

The results show that the proposed approach drives to a local voltage control setting effective in improving the network losses (the more HC, the more amount of losses [62] which is the proof of positive amount of losses here). The ORPF keeps the voltage profile higher than the standard control law in order to limit the network losses driving to better performances. It's worthwhile to underline how in the under investigation case (6 MW injection from DG unit) in the standard local control scenario, voltage violations are detected. The proposed set-up procedure allows both to an improvement in the grid losses and in a minimization of the voltage violations. The proposed approach proved to be a sound improvement with respect to the standard voltage control approach, resulting to be adequate for the short-medium term scenario, i.e. for those grids where the on-line ORPF approach is complex, or costly, to be implemented.

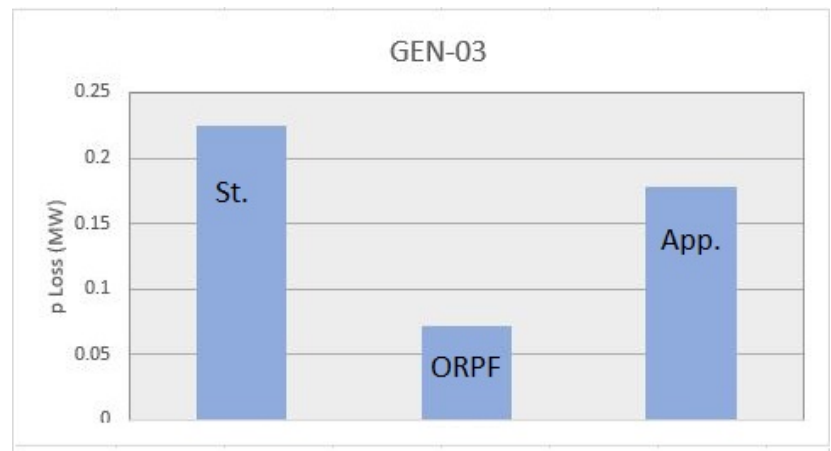

Fig. 5. Comparison between network losses of ORPF, standard local control and approximate local control at $6 M W$.

\section{CONCLUSION}

In this paper, different voltage control laws for distributed generation in the active distribution networks have been discussed. The control methods are classified into three main groups: local voltage control, coordinated voltage control and centralized voltage control. For each category, different research papers with various approaches are overviewed. Since plenty of sensors in smart architectures needed to be deployed, this can result unfeasible with respect to both the economic and the technical viability of the approach. Therefore, a new approach to set up the local control law was proposed. The results of the proposed method showed that the local operation based on a proper set-up could drive to good improvement in the management of the distribution grid voltage profile.

\section{REFERENCES}

[1] M. Bollen and M. Hger, Power quality: interactions between distributed energy resources, the grid, and other customers, Leonardo Energy, 2005.

[2] R. Walling, R. Saint, R. C. Dugan, J. Burke, and L. A. Kojovic, Summary of distributed resources impact on power delivery systems, IEEE Transactions on power delivery, vol. 23, pp. 1636-1644, 2008.

[3] J. P. Lopes, N. Hatziargyriou, J. Mutale, P. Djapic, and N. Jenkins, Integrating distributed generation into electric power systems: A review of drivers, challenges and opportunities, Electric power systems research, vol. 77, pp. 1189-1203, 2007.

[4] M. Delfanti, D. Falabretti, M. Merlo, G. Monfredini, and V. Olivieri, Dispersed generation in mv networks: performance of anti-islanding protections, in Harmonics and Quality of Power (ICHQP), 2010 14th International Conference on, 2010, pp. 1-6.

[5] M. Delfanti, M. Merlo, and G. Monfredini, Voltage Control on LV Distribution Network: Local Regulation Strategies for DG Exploitation, Research Journal of Applied Sciences, Engineering and Technology, vol. 7, pp. 4891-4905, 2014.

[6] S. M. Mirbagheri, M. Moncecchi, D. FalabrettiM, M. Merlo, Hosting Capacity Evaluation in case of Grid Parameters Uncertainties, in Harmonics and Quality of Power (ICHQP), 2018.

[7] A. Bonhomme, D. Cortinas, F. Boulanger, J.-L. Fraisse, A new voltage control system to facilitate the connection of dispersed generation to distribution networks, CIRED 2001, 18-21 June 2001, Amsterdam, Conference Publication No. 482, Page(s): 1-5.

[8] J.A. Pecas Lopes, N. Hatziargyriou, J. Mutale, P. Djapic, N. Jenkins, Integrating distributed generation into electric power system: A review of drivers, challenges and opportunities, Electric Power System Research, 77 (2007) 1189-1203, 2006, Page(s): 1-15.

[9] Italian Electrical Committee (CEI), 2012, Technical standard CEI 0-21 Reference technical rules for the connection of active and passive users to the LV electrical Utilities, in Italian, CEI, Milan.

[10] T. Soares, R. J. Bessa, P. Pinson, and H. Morais, "Active Distribution Grid Management based on Robust AC Optimal Power Flow," IEEE Transactions on Smart Grid, 2017.

[11] T. Sansawatt, L. F. Ochoa, and G. P. Harrison, Integrating distributed generation using decentralised voltage regulation, in Power and Energy Society General Meeting, 2010 IEEE, 2010, pp. 1-6.

[12] P. N. Vovos, A. E. Kiprakis, A. R. Wallace, G. P. Harrison, Centralized and distributed voltage control: impact on distributed generation penetration, IEEE Transactions on power systems 2007; 22: 473-483. DOI: 10.1109/TPWRS.2006.888982.

[13] C. Gao, M. A. Redfern, A review of voltage control techniques of networks with distributed generations using OnLoad Tap Changer transformers, 45th International Universities Power Engineering Conference (UPEC) (2010), 1-6.

[14] FA. Viawan, D. Karlsson, Coordinated voltage and reactive power control in the presence of distributed generation, Proceedings of the power and energy society general meeting on conversion and delivery of electrical energy in the 21st century, 2008.

[15] SK. Salman, F. Jiang, WJS. Rogers, Effects of wind power generators on the voltage control of utility distribution networks, Proceedings of the international conference on renewable energy clean power 2001; 1993.

[16] C. R. Sarimuthu, V. K. Ramachandaramurthy, K. Agileswari, and H. Mokhlis, A review on voltage control methods using on-load tap changer transformers for networks with renewable energy sources, Renewable and Sustainable Energy Reviews, vol. 62, pp. 1154-1161, 2016.

[17] M.E. Baran, M.Y. Hsu, Volt/VAr control at distribution substations, IEEE Trans Power Syst, 14 (1) (1999), pp. 312-318

[18] JH. Harlow, Transformer tap changing under load: a review of concepts and standards, Proceedings of the 64th annual engineering conference; 1993.

[19] F.A. Viawan, A. Sannino, J. Daalder, Voltage control with on-load tap changers in medium voltage feeders in presence of distributed generation, Electric Power Systems Research, 77 (2007) No.10, 1314 1322.

[20] A. Kulmala, K. Maki, S. Repo, P. Jarventausta, Including active voltage level management in planning of distribution networks with distributed generation, IEEE Bucharest PowerTech (2009), 1-6.

[21] S. N. Salih, P. Chen, On coordinated control of OLTC and reactive power compensation for voltage regulation in distribution systems with wind 
power, IEEE Transactions on Power Systems, vol. 31, pp. 4026-4035, 2016.

[22] K. Turitsyn, P. Sulc, S. Backhaus, M. Chertkov, Local Control of Reactive Power by Distributed Photovoltaic Generators, First IEEE International Conference on Smart Grid Communications (2010), 79 84.

[23] M. Elnashar, M. Kazerani, R. El Shatshat, M. M. A. Salama, Comparative evaluation of reactive power compensation methods for a stand-alone wind energy conversion system, IEEE Power Electronics Specialists Conference (2008), 4539- 4544

[24] M. Aggarwal, S. K. Gupta, M. Madhusudan, G. Kasal, DSTATCOM Control in Low Voltage Distribution System with Distributed Generation, 3rd Int. Conf. on Emerging Trends in Engineering and Technology (ICETET) (2010), 426-429.

[25] D. Caples, S. Boljevic, M. F. Conlon, Impact of distributed generation on voltage profile in $38 \mathrm{kV}$ distribution system, 8th International Conference on the European Energy Market (EEM) (2011), 532-536

[26] D. Kumar, S. R. Samantaray, Implementation of multi-objective seekeroptimization-algorithm for optimal planning of primary distribution systems including DSTATCOM, International Journal of Electrical Power and Energy Systems 77 (2016), 439-449.

[27] T. Sansawatt, J. O’Donnell, L. F. Ochoa, G. P. Harrison , Decentralised voltage control for active Distribution Networks, in Universities Power Engineering Conference (UPEC), 2009 Proceedings of the 44th International, 2009, 1-5.

[28] T. Sansawatt, L. F. Ochoa, G. P. Harrison, Decentralised Voltage and Thermal Management to enable more Distributed Generation Connection, presented at the CIRED Workshop, Lyon, 2010.

[29] D. Ranamuka, A. P. Agalgaonkar, K. M. Muttaqi, Examining the interactions between DG units and voltage regulating devices for effective voltage control in distribution systems, IEEE Transactions on Industry Applications 53.2 (2017): 1485-1496.

[30] W. Freitas, J. C. Vieira, A. Morelato, W. Xu, Influence of excitation system control modes on the allowable penetration level of distributed synchronous generators, Energy Conversion, IEEE Transactions on, (2005) No.20, 474-480.

[31] M. Delfanti, L. Frosio, G. Monfredini, M. Merlo, C. Rosati, D. Rosati, et al., Technical Strategies for Voltage Power Regulation in LV Distribution Networks, Distributed Generation and Alternative Energy, p. 7, 2015

[32] C.M. Hird, H.Leite, N. Jenkins, andH.Li, Network voltage controller for distributed generation, IEE Proc., Gener. Transm. Distrib., vol. 151, pp. 150156, Mar. 2004.

[33] M. E. Baran, I. M. El-Markabi, A multiagent-based dispatching scheme for distributed generators for voltage support on distribution feeders, IEEE Trans. Power Syst., vol. 22, pp. 5259, Feb. 2007.

[34] K. A. Alobeidli, M. H. Syed, M. S. El Moursi, H. H. Zeineldin, Novel coordinated voltage control for hybrid micro-grid with islanding capability, IEEE Transactions on Smart Grid, vol. 6, pp. 1116-1127, 2015.

[35] H. Hiroyuki, H. Kobayashi, A Study of Centralized Voltage Control Method for Distribution System with Distributed Generation, 19th International Conference on Electricity Distribution (2007).

[36] A. Kulmala, S. Repo, and P. Jrventausta, Increasing penetration of distributed generation in existing distribution networks using coordinated voltage control, Int. J. Distrib. Energy Resources, vol. 5, pp. 227255 , Jul. 2009.

[37] F. Bignucolo, R. Caldon, and V. Prandoni, Radial MV networks voltage regulation with distribution management system coordinated controller Electr. Power Syst. Res., vol. 78, pp. 634645, Apr. 2008

[38] S. Conti and A. M. Greco, Innovative voltage regulation method for distribution networks with distributed generation, in Proc. 19th Int. Conf. Electr. Distrib., 2007.

[39] Q. Zhou and J. W. Bialek, Generation curtailment to manage voltage constraints in distribution networks, IET Gener. Transm. Distrib, vol. 1, pp. 492498, May 2007.

[40] P. H. Nguyen, J. M. A. Myrzik, and W. L. Kling, Coordination of voltage regulation in active networks, in Proc. IEEE PES Transm. Distrib. Conf. Expo., 2008.

[41] H. E. Z. Farag, E. F. El-Saadany, R. Seethapathy, A two ways communication-based distributed control for voltage regulation in smart distribution feeders, IEEE Trans. Smart Grid, vol. 3, pp. 271281, Mar 2012.
[42] T. Senjyu, Y. Miyazato, A. Yona, N. Urasaki, T. Funabashi, Optimal distribution voltage control and coordination with distributed generation, IEEE Trans. Power Del., vol. 23, pp. 12361242, Apr. 2008.

[43] N. Nimpitiwan and C. Chaiyabut, Centralized control of system voltage/reactive power using genetic algorithm, in Proc. Int. Conf. Intell. Syst. Appl. Power Syst., 2007.

[44] T. Niknam, A. M. Ranjbar, and A. R. Shirani, Impact of distributed generation on volt/var control in distribution networks, in Proc. Power Tech, 2003.

[45] A. G. Madureira and J. A. Pecas Lopes, Coordinated voltage support in distribution networks with distributed generation and microgrids, IET Renew. Power Gener., vol. 3, pp. 439454, Dec. 2009.

[46] A. Kulmala, S. Repo, and P. Jarventausta, Coordinated voltage control in distribution networks including several distributed energy resources, IEEE Transactions on Smart Grid, vol. 5, pp. 2010-2020, 2014.

[47] V. Galdi, A. Vaccaro, and D. Villacci, Voltage regulation in MV networks with dispersed generations by a neural-based multiobjective methodology, Electr. Power Syst. Res., vol. 78, pp. 785793, May 2008.

[48] K. Mehmood, S. Khan, S. Lee, Z. M. Haider, M. K. Rafique, and C.Kim, A real-time optimal coordination scheme for the voltage regulation of a distribution network including an OLTC, capacitor banks, and multiple distributed energy resources, International Journal of Electrical Power and Energy Systems, vol. 94, pp. 1-14, 2018.

[49] D. Ranamuka, A. P. Agalgaonkar, and K. M. Muttaqi, Online coordinated voltage control in distribution systems subjected to structural changes and DG availability, IEEE Transactions on Smart Grid, vol. 7 , pp. 580-591, 2016

[50] A. Angioni, A. Sadu, F. Ponci, A. Monti, D. Patel, F. Williams, et al. Coordinated voltage control in distribution grids with LTE based communication infrastructure, in Environment and Electrical Engineering (EEEIC), 2015 IEEE 15th International Conference on, 2015, pp. 20902095.

[51] A. Berizzi, C. Bovo, M. Merlo, M. Delfanti, A ga approach to compare orpf objective functions including secondary voltage regulation, Electric Power Systems Research 84.1 (2012): 187-194.

[52] M. Delfanti, D. Falabretti, M. Fiori, M. Merlo, Smart Grid on field application in the Italian framework: The AS SE. M. project, Electric Power Systems Research 120 (2015): 56-69.

[53] A. Berizzi, C. Bovo, C. Bruno, M. Delfanti, M. Merlo, M. Pozzi, ORPF procedures for voltage security in a market framework, Power Tech, 2005 IEEE Russia. IEEE, 2005

[54] D. Jakus, J. Vasilj, P. Sarajcev, Voltage control in $M V$ distribution networks through coordinated control of tap changers and renewable energy sources, 2015 IEEE Eindhoven PowerTech, PowerTech 2015 2015.

[55] W. Sheng, S. Member, K. Liu, S. Cheng, X. Meng, W. Dai, A Trust Region SOP Method for Coordinated Voltage Control in Smart Distribution Grid, vol. 7, no. 1, pp. 381391, 2016.

[56] S. Santoso, N. Saraf, G. K. Venayagamoorthy, Intelligent Techniques for Planning Distributed Generation Systems, IEEE Power Engineering Society General Meeting (2007), 1-4.

[57] S. Kawano, S. Yoshizawa, Y. Hayashi, Centralized voltage control method using voltage forecasting by JIT modeling in distribution networks, Transmission and Distribution Conference and Exposition, 2016 IEEE/PES. IEEE, 2016.

[58] Z. Hu, X. Wang, H. Chen, G. A. Taylor, Volt/VAr control in distribution systems using a time-interval based approach, IEEE Proceedings on Generation, Transmission and Distribution, 150 (2003) No.5, 548-554.

[59] S. S. Alkaabi, H. H. Zeineldin, V. Khadkikar, M. S. Elmoursi, Dynamic analysis of OLTC and voltage regulator under active network management considering different load profiles, Power and Energy Society Innovative Smart Grid Technologies Conference (ISGT), 2017 IEEE. IEEE, 2017

[60] T. T. Hashim, A. Mohamed, H. Shareef, A review on voltage control methods for active distribution networks, Prz. Elektrotech 88 (2012): 304-312.

[61] M. Gallanti, M. Merlo, D. Moneta, P. Mora, G. Monfredini, V. Olivieri, MV network with Dispersed Generation: voltage regulation based on local controllers, paper 0934, 21th International Conference on electricity Distribution CIRED, Frankfurt, 6-9 June 2011, Page(s): 1-4

[62] M. Delfanti, D. Falabretti, M. Merlo, Dispersed generation impact on distribution network losses, Electric Power Systems Research 97 (2013): 10-18. 